\title{
Off-pump versus on-pump coronary artery bypass grafting surgery in high-risk patients: PRAGUE- 6 trial at 30 days and 1 year
}

\author{
Jan Hlavicka ${ }^{\mathrm{a}}$ Zbynek Straka ${ }^{\mathrm{a}}$, Stepan Jelinek ${ }^{\mathrm{a}}$, Petr Budera ${ }^{\mathrm{a}}$, Tomas Vanek ${ }^{\mathrm{a}}$, Marek Maly ${ }^{\mathrm{b}}$, Petr Widimsky ${ }^{\mathrm{a}}$
}

\begin{abstract}
Aims. Off-pump coronary artery bypass graft surgery (OPCAB) is an established alternative to on-pump surgical revascularization. Previous studies in patients with low or intermediate risk showed no significant differences between off-pump and on-pump surgical revascularization. The aim of this study was to compare the two techniques in patients with high operative risk.

Methods. PRAGUE- 6 is a prospective randomized single-center study of 206 patients, with an additive EuroSCORE $\geq 6$, scheduled for isolated coronary surgery: Group A - on-pump $(n=108)$ versus Group B - off-pump $(n=98)$. The primary outcome was a combined endpoint of all-cause deaths, stroke, myocardial infarction, or renal failure requiring new hemodialysis, within 30 days and 1 year after randomization. All data were analyzed using the "intention-to-treat" principle. Results. Early postoperative myocardial infarction was detected in $12.1 \%(\mathrm{~A})$ vs. $4.1 \%(\mathrm{~B})$ of patients $(P=0.048$, hazard ratio $0.32,95 \% \mathrm{Cl} 0.11-0.99)$. There was a significantly higher incidence of primary combined end-point in group $A$ (20.6\% vs. 9.2\%, $P=0.028$, HR 0.41, 95\% Cl 0.19-0.91) in the first 30 days, but not after 1 year $(30.8 \%$ vs. $21.4 \%, P=0.117$, HR 0.65, Cl 0.37-1.12).

Conclusion. Off-pump surgical revascularization in patients with high operative risks can significantly reduce the incidence of major postoperative complications during the first 30 days. There was no statistically significant difference in the incidence of these complications after 1 year.
\end{abstract}

Key words: revascularization, cardiopulmonary bypass, off-pump, high-risk patient

Received: June 14, 2015; Accepted with revision: November 20, 2015; Available online: January 5, 2016 http://dx.doi.org/10.5507/bp.2015.059

${ }^{a}$ Cardiocentre, University Hospital Kralovske Vinohrady and Third Faculty of Medicine, Charles University in Prague, Czech Republic ${ }^{b}$ National Institute of Public Health, Prague, Czech Republic

Corresponding author: Jan Hlavicka, e-mail:jan.hlavicka@centrum.cz

\section{INTRODUCTION}

The off-pump coronary surgery (OPCAB) was developed in the 1960s and revived in the 1990s. Among other things, it was expected to reduce operative trauma ${ }^{1-2}$, incidence of serious post-operative complications ${ }^{3}$ and thus decrease mortality. The results from patient surgery without the use of cardiopulmonary bypass (CPB), in a group of consecutive non-selected patients, have been promising ${ }^{4}$. However, several randomized trials comparing off-pump and on-pump techniques conducted in recent years have failed to demonstrate any significant differences in mortality, stroke, myocardial infarction, or new renal failure. It should be noted that all these randomized controlled trials were conducted in relatively low-risk patients $^{5-7}$. For high-risk patients undergoing off-pump surgery, some retrospective studies showed better in-hospital outcomes $^{8.9}$. However, the continued lack of prospective randomized studies on high-risk patients remains a significant issue ${ }^{10}$. We decided to test the potential benefits of OPCAB during the first 30-days and 1-year after the procedure, in candidates with an additive EuroSCORE $\geq$ 6 and in a prospective randomized trial.

\section{MATERIALS AND METHODS}

Study design

The PRAGUE-6 trial was designed as a single-center study with consecutively randomized high-risk patients selected for on-pump or off-pump coronary artery surgery only. The primary hypothesis was that the off-pump technique would reduce major postoperative events in the first 30 postoperative days as well as in the mid-term followup at 1 year. All patients provided written informed consent. The study protocol was approved by the Institutional Ethics Committee (IEC). All participating surgeons were required to have experience with at least 100 revascularization procedures using both techniques.

\section{Patients and randomization}

According to the additive EuroSCORE, patients with a preoperative score $\geq 6$ were assessed as being at high-risk and were included in the study assuming they met the other inclusion criteria such as: age greater than 18 years, isolated CABG (primary or redo surgery) for left main disease (LMD) and/or 1 to 3 vessel disease (1 to 3VD), elective or sub-acute surgery, and written informed consent. The exclusion criteria included less than 18 years of age, other than isolated CABG, emergency surgery requiring immediate intervention, participation in another clini- 
cal study, and lack of informed consent. Randomization was carried out using the envelope method and managed by an independent third party. Surgeons, however, had full discretion to change the technique at any time during the procedure.

\section{Anesthetic and surgical technique}

In all cases, standard monitoring of invasive arterial and central venous pressures, temperature, pulse oximetry and five-lead electrocardiogram (ECG) was used. In patients with a left ventricle ejection fraction (LVEF) less than $20 \%$, a pulmonary artery catheter was used. After supine positioning of the patient, general anesthesia was started using midazolam 5-10 mg, sufentanil 20 to $30 \mu \mathrm{g}$ and propofol $50-150 \mathrm{mg}$. Tracheal intubation followed muscle relaxation with intravenous atracurium $50 \mathrm{mg}$. Anesthesia was maintained using inhaled isoflurane and additional sufentanil up to a total dose $150 \mu \mathrm{g}$. Postoperative ICU management was based on the fast-track protocol, which has been used in our department, with varying modifications, for many years ${ }^{11}$. Surgical access was through a median sternotomy in all patients. The left internal mammary artery was used as the graft, and the great or small saphenous vein was either harvested using an open technique or endoscopically. All surgeries took place under normothermic conditions.

\section{Group A-On Pump}

On-pump surgery was performed using standard ascending aorta cannulation and two-stage venous cannulation of the right atrium. The goal of an activated clotting time (ACT) of 480 seconds was reached through administration of $300 \mathrm{IU} / \mathrm{kg}$ of heparin, which was neutralized by protamine sulphate, at the end of the procedure. For the achievement of cardiac arrest we routinely used aortic cross-clamping and induction of intermittent antegrade cold crystalloid "St. Thomas" cardioplegia.

\section{Group B-Off-Pump}

Heparin was given at a dose of 100 to $200 \mathrm{IU} / \mathrm{kg}$. The target ACT was > $250 \mathrm{~s}$. For elevation and stabilization of the heart and target vessels the Acrobat - $\mathrm{i}{ }^{\circledR}$ vacuum system (Maquet Cardiovascular, LLC, Wayne, NJ, U.S.A.) was used. A peripheral anastomosis was created using a Clearwiev ${ }^{\circledR}$ intracoronary shunt (Medtronic, Inc., Minneapolis, MN, U.S.A.). A side-biting aortic clamp was applied during suturing of the central anastomosis of the venous graft. In cases were the ascending aorta was sclerotic, the Heartstring III Proximal Seal System ${ }^{\circledR}$ (Maquet Cardiovascular, Llc., Wayne, NJ, U.S.A.) was used.

\section{Study endpoints and outcome definition}

The combined primary endpoint of our study was defined as death, stroke, myocardial infarction, or new renal failure requiring dialysis within the first 30 postoperative days. Death was specified as all-cause death. Stroke was determined as a neurologic deficit persisting for more than $24 \mathrm{~h}$, confirmed by a neurologist and/or an imaging method (CT or MRI). Myocardial infarction was defined according to the recommendations of the
European Society of Cardiology and Society of Thoracic Surgeons Adult Cardiac Database Definition of Terms Version 2.52.1. Specifically, biomarker values (CK-MB, CKMB mass) above five times the 99th percentile of the normal reference range during the first 72 hours after surgery and/or new pathological Q-waves in two or more contiguous ECG leads, or a new left bundle branch block (LBBB), and/or a documented new occlusion of the graft or a coronary artery, or echocardiographic evidence of loss of previously viable myocardium ${ }^{12-13}$. After more than $72 \mathrm{~h}$ post-operative, an MI was defined by an elevation of biomarker values above the 99th percentile of the upper limit of the norm, associated with at least one additional event: ECG changes indicating new ischemia, development of new $Q$ waves, symptoms of cardiac ischemia, and any newly occurring regional wall motion abnormality confirmed using any available imaging method. Renal failure was defined as a new requirement for hemodialysis. Indications for the initiation of continuous renal replacement therapy were as follows: diuretic resistant oliguria together with signs of volume overload, severe hyperkalemia, and/or metabolic acidosis in the immediate post-operative period, plus a rise of the blood urea levels exceeding $35 \mathrm{mmol} / \mathrm{L}$ ( $98 \mathrm{mg} / \mathrm{dL}$ ). Sub-acute coronary bypass surgery was performed in patients waiting in hospital for revascularization after an acute coronary syndrome, i.e. angina or myocardial infarction. To define those patients at high risk we used the additive EuroSCORE. The clinical outcomes included in the primary combined endpoint were reassessed one year after randomization.

\section{Statistical methods}

We concentrated on the early postoperative results in the first 30 days and expected the incidence of the primary combined endpoint in about $10 \%$ of the off-pump cases and in $25 \%$ of the patients operated on-pump, with an expected hazard ratio of 0.35 . Based on this assumption, a sample size of 95 subjects per group was required to assure a statistical power of at least 0.8 to detect the between-group differences in the Cox's regression model. Data were collected prospectively during patient hospitalization, as part of routine practice, and after discharge during follow-up by our outpatient department and by the Czech National Health Insurance Registry. The central tendency and variability of continuous data was expressed as an arithmetic mean and standard deviation (SD) for normally distributed variables or as the median and interquartile range (IQR) for log-normally distributed variables. Normality was tested using the Shapiro-Wilk test. Comparisons of groups were based on the Student's two-sample t-test and the Mann-Whitney test. For categorical data, the differences in proportions between groups were analyzed using the Fisher's exact test and its generalization and by the Pearson's $\chi 2$ test. The strength of association was quantified using relative risk (RR) and the corresponding 95\% confidence interval (CI). Data regarding the site of the distal anastomosis was analyzed using a multinomial regression model with standard errors adjusted for intragroup correlations. The time to the first occurrence of any component of the composite endpoint 
was characterized using a Kaplan-Meier failure curve and comparison of groups was based on the Cox's proportional hazards model with a hazard ratio (HR) used as a measure of association. The Therneau and Grambsch non-proportionality test was used to check the assumption of the Cox model. All analyses were conducted on the "intention-to-treat" principle. The combined primary endpoint and its components were additionally compared in a per protocol manner. All statistical tests were treated as two-sided and evaluated at a significance level of 0.05 . Statistical analysis was carried out using Stata, release 9.2 statistical software (Stata Corp LP, College Station, TX).

\section{RESULTS}

\section{Patients}

Between June 2006 and July 2011 we randomized 206 patients to the PRAGUE-6 trial: 108 into group A (on-pump) and 98 into group B (off-pump). A total of 6 patients did not undergo surgery: 1 patient withdrew her consent, 4 underwent emergency percutaneous coronary intervention (PCI) because of an acute myocardial infarction (MI) and 1 patient died before surgery. Ultimately, surgery was conducted on 106 and 94 patients, Group A and $\mathrm{B}$, respectively. One patient from group A was lost during the follow-up and could not be included in the final 30 -day and 1-year results of the primary composite outcome. Nevertheless we reached $99.5 \%$ of enrolled patient outcomes. There were no significant differences between groups from a demographic point of view (Table 1).

\section{Perioperative and early postoperative data}

The higher mean number of anastomoses per patient in group A had statistical significance $(P<0.001)$, as well as differences in bypass distribution, especially in the area of the circumflex artery. Surgeons used the LIMA equally in both groups (Table 2). The early postoperative course is documented in Table 3. Although we did not see any differences in blood loss between groups, the need for red blood cells (RBC) transfusions was significantly higher in patients undergoing the on-pump procedure. Other early post-operative parameters were similar in both groups. There were 8 conversions from off-pump to onpump during surgery: Four patients converted because of hemodynamic instability (two of them with an EF of $20 \%$ ), three patients due to extensive pericardial adhesions complicating preparation of the coronary arteries and one patient due to the deep intramuscular course of the $\mathrm{LAD}$, and conversion was required to prevent injury to the ventricular wall.

\section{Primary endpoints - 30 days}

The primary combined endpoint at 30 days occurred in $20.6 \%$ of on-pump patients and in $9.2 \%$ of off-pump patients, a difference that was statistically significant ( $P=0.028$, HR for off-pump $0.42,95 \%$ CI $0.19-0.91)$. In addition, the occurrence of acute myocardial infarction in group A was more than three times higher than in (off-pump) group B. See Table 4. In the on-pump group

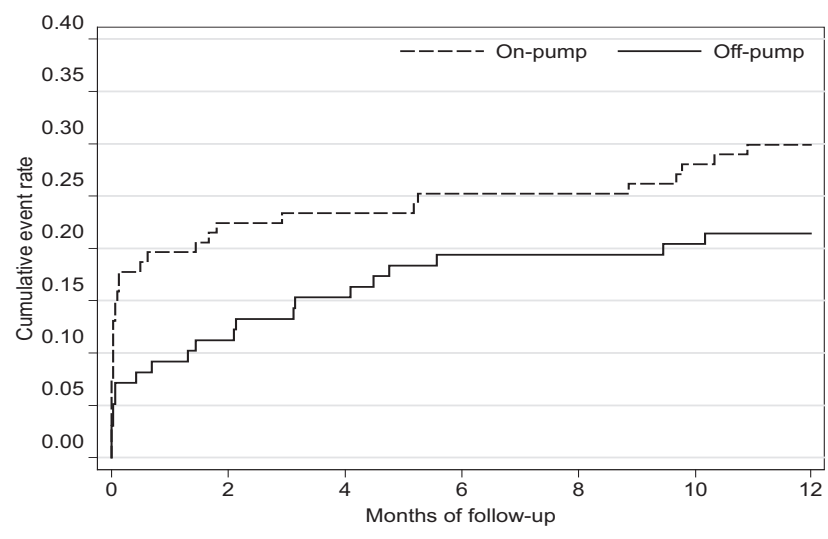

Fig. 1. Kaplan-Meier curves. The incidence of combined primary end point during the first postoperative year.

there were 4 re-coronarographies performed in the early postoperative period, but only one re-intervention due to a demonstrated graft occlusion. In the subgroup of patients who had a procedural change (i.e. off-pump to on-pump) there were 2 primary endpoints before day 30 .

\section{Primary endpoints - 1 year}

At one year (between 0-365 days) the primary combined endpoint occurred in 33 (30.8\%) of on-pump patients, and in $21(21.4 \%)$ of off-pump participants $(P=$ 0.117, HR 0.65, 95\% CI 0.37-1.12) (Table 4). Differences in the primary endpoint at 1 year were not significant between groups. The highest incidence of the primary combined end-point was prior to the fourth post-operative day. After one month the incidences rates ran parallel courses (Fig. 1). One of the converted patients had a stroke 137 days after randomization.

\section{DISCUSSION}

To determine high-risk patients we used the EuroSCORE, which is widely used and has proven to have significantly better discriminatory power than the Society of Thoracic Surgeons, Risk Algorithm ${ }^{14}$. In our study, the expected mortality substantially overestimated the operative risk compared to what we experienced, in both groups, during the first 30 days following surgery, and is a potential argument for using a new risk classification algorithm, especially in high-risk patients.

\section{Early Outcomes}

The PRAGUE-6 study is one of the prospective randomized trials examining "on-pump vs. off-pump in highrisk patients". Studies with the same primary endpoints, such as the PRAGUE-4, ROOBY, and CORONARY, demonstrate no significant differences in early postoperative mortality and morbidity ${ }^{5-7}$. All of the above trials enrolled low-risk patients in whom the usage of extracorporeal circulation is usually well tolerated and therefore the potential benefits of the off-pump technique might not be obvious. In these patients the chosen method does not influence the incidence of serious post- 
Table 1. Preoperative demographic data.

\begin{tabular}{|c|c|c|c|}
\hline Variable & $\begin{array}{c}\text { Group A } \\
\text { On-Pump (108) }\end{array}$ & $\begin{array}{c}\text { Group B } \\
\text { Off-Pump (98) }\end{array}$ & $P$ \\
\hline Age $(y r)$ - mean $( \pm S D)$ & $73.6( \pm 7.4)$ & $74.7( \pm 6.5)$ & 0.280 \\
\hline Female gender - no. (\%) & $46(42.6)$ & $40(40.8)$ & 0.888 \\
\hline Hypertension (\%) & $90(83.3)$ & $82(83.7)$ & 1.000 \\
\hline Diabetes mellitus (\%) & $50(46.3)$ & $47(48.0)$ & 0.889 \\
\hline CVA (\%) & $13(12.0)$ & $16(16.3)$ & 0.426 \\
\hline Renal impairment (\%) & $9(8.3)$ & $14(14.3)$ & 0.191 \\
\hline Previous transmural MI (\%) & $34(31.5)$ & $28(28.6)$ & 0.761 \\
\hline Recent MI (\%) & $73(67.6)$ & $58(59.2)$ & 0.247 \\
\hline Previous PCI (\%) & $23(21.3)$ & $22(22.4)$ & 0.867 \\
\hline Redo operation (\%) & $2(1.9)$ & $2(2.0)$ & 1.000 \\
\hline Angina class - no. (\%) & & & 0.033 \\
\hline $\operatorname{CCS} 0$ & $25(23.2)$ & $20(20.4)$ & \\
\hline CCS I & $12(11.1)$ & $8(8.2)$ & \\
\hline CCS II & $19(17.6)$ & $34(34.7)$ & \\
\hline CCS III & $32(29.6)$ & $16(16.3)$ & \\
\hline CCS IV & $20(18.5)$ & $20(20.4)$ & \\
\hline CAD extent - no. (\%) & & & 0.633 \\
\hline 0 vd (LMD) & $0(0.0)$ & $1(1.0)$ & \\
\hline $1 \mathrm{vd}$ & $4(3.7)$ & $6(6.1)$ & \\
\hline $2 \mathrm{vd}$ & $19(17.6)$ & $19(19.4)$ & \\
\hline $3 \mathrm{vd}$ & $85(78.7)$ & $72(73.5)$ & \\
\hline Ejection fraction - no. (\%) & & & 0.885 \\
\hline Normal $>0.5$ & $51(47.2)$ & $43(43.9)$ & \\
\hline Moderate $0.31-0.5$ & $45(41.7)$ & $44(44.9)$ & \\
\hline Poor $<=0.3$ & $12(11.1)$ & $11(11.2)$ & \\
\hline Surgery - no. (\%) & & & 0.416 \\
\hline Elective & $99(91.7)$ & $93(94.9)$ & \\
\hline Sub-acute & $9(8.3)$ & $5(5.1)$ & \\
\hline EuroSCORE add.- mean $( \pm$ SD $)$ & $7.66( \pm 1.49)$ & $7.69( \pm 1.76)$ & 0.872 \\
\hline EuroSCORE log.- mean $( \pm$ SD) & $9.81( \pm 5.11)$ & $10.69( \pm 8.55)$ & 0.849 \\
\hline
\end{tabular}

CAD - coronary artery disease, CCS - Canadian Cardiovascular Society Grading System score, CVA - cerebro-vascular accident, LMD - left main disease, MI - myocardial infarction, PCI - percutaneous coronary intervention.

operative complications. In ROOBY, the risk of death before discharge or within 30 days of the procedure was preoperatively estimated at less than $2 \%$ in both groups, and in CORONARY more than $80 \%$ of patients had an additive EuroSCORE of less than 6. In comparison with other most recent trials focused on high-risk patients, our study is similar to the Best Bypass Study (BBS). High-risk patients typically have higher rates of early post-operative complications but despite this fact we found a significant reduction in post-operative morbidity in off-pump patients within the first 30 post-operative days. The most important difference between The Best Bypass Surgery Trial and the PRAGUE- 6 trial can be seen in the enrollment criteria for the BBS trial: additive EuroSCORE $\geq 5$, three-vessel disease, and left ventricular ejection fraction > than $30 \%$. As mentioned above, more than $11 \%$ of our patients had poor ejection fraction, and about one fifth of them had left main disease or 1- or 2-vessel disease. Additionally, the lower additive EuroSCORE in the BBS Trial (mean 6.9) compared to the PRAGUE 6 trail (mean > 7.5) suggests that we generally enrolled more seriously ill patients ${ }^{15}$. Lemma 's randomized study is the trial most similar to ours; they also found a significant reduction in serious early post-operative complications in the off-pump group, although the primary combined end-point was defined in a slightly different way with the addition of reoperation for bleeding and acute respiratory distress syndrome ${ }^{16}$.

In the first 30 days we observed a significantly lower incidence of non-fatal MI in the off-pump group. The definition of post-operative MI has been somewhat flexible in other trials which is why we chose stricter criteria for myocardial damage taking into account a variety of 
Table 2. Perioperative data (intention-to-treat)*.

\begin{tabular}{|c|c|c|c|}
\hline Variable & $\begin{array}{c}\text { Group A } \\
\text { On-Pump (106) }\end{array}$ & $\begin{array}{c}\text { Group B } \\
\text { Off-Pump (94) }\end{array}$ & $P$ \\
\hline Converted - no. (\%) & $0(0.0)$ & $8(8.5)$ & 0.002 \\
\hline No. of distal anastomoses & 282 & 192 & \\
\hline No. of distal anastomoses/pt & 2.66 & 2.04 & $<0.001$ \\
\hline Heartstring III $®$ - no. (\%) & & $11(11.7)$ & \\
\hline Site of distal anastomosis- no. (\%) & & $<0.001$ & \\
\hline $\operatorname{LAD}(\%)$ & $121(42.9)$ & $112(58.3)$ & \\
\hline $\mathrm{RCx}(\%)$ & $87(30.9)$ & $43(22.4)$ & \\
\hline RCA $(\%)$ & $74(26.2)$ & $37(19.3)$ & \\
\hline LIMA use (\%) & $101(95.3)$ & $88(93.6)$ & 0.759 \\
\hline EVH (\%) & $29(27.4)$ & $23(24.5)$ & 0.747 \\
\hline $\mathrm{CP}$ bypass time $(\min )-$ mean $( \pm \mathrm{SD})$ & $52.5( \pm 19.7)$ & & \\
\hline Cross-clamp time $(\mathrm{min})-$ mean $( \pm \mathrm{SD})$ & $30.3( \pm 11.6)$ & & \\
\hline Total time of surgery $(\mathrm{min})-$ mean $( \pm \mathrm{SD})$ & $153( \pm 20)$ & $140( \pm 24)$ & $<0.001$ \\
\hline
\end{tabular}

* really operated patients, CP -cardio-pulmonary, LAD - left anterior descend artery, LIMA - left internal mammary artery, min - minutes, No. number, pt - patient, RCx - circumflex artery, RCA - right coronary artery, EVH - endoscopic vein harvesting, SD - standard deviation

Table 3. Postoperative data (intention-to-treat) ${ }^{*}$.

\begin{tabular}{|c|c|c|c|c|}
\hline Variable & $\begin{array}{c}\text { Group A } \\
\text { On-Pump( 106) }\end{array}$ & $\begin{array}{c}\text { Group B } \\
\text { Off-Pump (94) }\end{array}$ & $P$ & RR ( 95\%CI ) \\
\hline \multicolumn{5}{|l|}{ Total blood loss (mL) } \\
\hline - median (IQR) & $485(400)$ & $535(350)$ & 0.577 & \\
\hline Need for RBC transfusion (\%) & $85(80.2)$ & $61(64.9)$ & 0.017 & $0.81(0.68-0.97)$ \\
\hline Transfuse units - mean $( \pm$ SD $)$ & $3.5( \pm 2.8)$ & $3.0( \pm 1.6)$ & 0.139 & \\
\hline Re-exploration for bleeding (\%) & $9(8.5)$ & $3(3.2)$ & 0.143 & $0.38(0.10-1.35)$ \\
\hline LCO - no. (\%) & $29(27.4)$ & $20(21.3)$ & 0.329 & $0.78(0.47-1.28)$ \\
\hline \multicolumn{5}{|l|}{ Time of intubation (h) } \\
\hline - median (IQR) & $2(5)$ & $2(4)$ & 0.227 & \\
\hline $\operatorname{IABP}(\%)$ & $4(3.8)$ & $2(2.1)$ & 0.686 & \\
\hline Wound infection (\%) & $5(4.7)$ & $2(2.1)$ & 0.451 & $0.45(0.09-2.27)$ \\
\hline New atrial fibrillation (\%) & $41(38.7)$ & $37(39.4)$ & 1.000 & $1.02(0.72-1.44)$ \\
\hline \multicolumn{5}{|l|}{ Hospital stay (d) } \\
\hline - median (IQR) & $6(2)$ & $6(2)$ & 0.280 & \\
\hline \multicolumn{5}{|l|}{ Total hospital cost (EUR) } \\
\hline - median (IQR) & $8205(2353)$ & $8051(2856)$ & 0.149 & \\
\hline
\end{tabular}

* really operated patients, CI - confidence interval, d - days, EUR - Euro, h - hours, IQR - interquartile range, LCO - low cardiac output, mL - milliliter, RBC - red blood cells, RR - relative risk

clinical manifestations. Additionally, a so-called laboratory myocardial infarction, as an indicator of a mid-term harmful effect, should not be underestimated, as Paparela et al. demonstrated ${ }^{17}$. The definition of a post-operative myocardial infarction used in this study was suggested in 2004 by the Society of Thoracic Surgeons, as well as in 2011 by the European Society of Cardiology. ROOBY and CORONARY, the largest studies on this topic, also utilize the same definition.

The question of the higher incidence of early postoperative myocardial infarctions in on-pump patients still remains. The widely accepted clinical PREVENT IV study identified such intraoperative risk factors for perioperative MI as prolonged cardiopulmonary bypass or aortic cross-clamp times, perioperative myocardial ischemia, and inadequate revascularization. In addition, patients with perioperative MI were found to have had longer surgery durations, were older, had left main coronary artery disease and three-vessel disease (3-VD), impaired left ventricular function, unstable angina, recent MI, and a history of emergency operations. Also, venous graft failure was common and associated with both patient and surgical fac- 
Table 4. Results after 30 days and after 1 year (intention-to-treat)".

\begin{tabular}{lcccc}
\hline Results after 30 days & $\begin{array}{c}\text { Group A } \\
\text { On-Pump (107) }\end{array}$ & $\begin{array}{c}\text { Group B } \\
\text { Off-Pump (98) }\end{array}$ & $P$ & HR (95\% CI) \\
\hline Combined prim. endpoint - no. (\%) & $22(20.6)$ & $9(9.2)$ & 0.028 & $0.41(0.19-0.91)$ \\
Death & $6(5.6)$ & $4(4.1)$ & 0.623 & $0.73(0.21-2.58)$ \\
AMI & $13(12.1)$ & $4(4.1)$ & 0.048 & $0.32(0.11-0.99)$ \\
Stroke & $3(2.8)$ & $2(2.0)$ & 0.726 & $0.73(0.12-4.35)$ \\
Hemodialysis required & $5(4.7)$ & $1(1.0)$ & 0.163 & $0.22(0.03-1.85)$ \\
Coronary re-intervention & $1(0.9)$ & $1(1.0)$ & 0.953 & $1.09(0.07-17.37)$ \\
\hline & & & & \\
\hline Results after 1 year & Group A & Group B & HR (95\% CI) \\
\hline Combined prim. endpoint - no. (\%) & $33(30.8)$ & $21(21.4)$ & 0.117 & $0.65(0.37-1.12)$ \\
Death & $11(10.3)$ & $16(16.3)$ & 0.210 & $1.63(0.76-3.52)$ \\
AMI & $16(15.0)$ & $8(8.2)$ & 0.148 & $0.53(0.23-1.25)$ \\
Stroke & $5(4.7)$ & $2(2.0)$ & 0.323 & $0.44(0.08-2.26)$ \\
Hemodialysis required & $6(5.6)$ & $1(1.0)$ & 0.113 & $0.18(0.02-1.50)$ \\
Coronary re-intervention & $3(2.8)$ & $5(5.1)$ & 0.373 & $1.92(0.46-8.02)$ \\
\hline
\end{tabular}

\# without one patient lost to 30days and 1 year follow-up, AMI - acute myocardial infarction, HR - hazard ratio

tors including, poor quality target arteries, longer surgery durations, and the use of endoscopic vein harvesting ${ }^{18}$. As shown in Table 2, the length of the procedure was obviously longer in ONCAB procedures, which could be one reason for a higher incidence of post-operative $\mathrm{MI}$ in this group. Our study did not exclude patients with diffuse coronary atherosclerosis from randomization, compared to other trials (e.g. ROOBY). It is not unexpected, that in a population with $46 \%$ diabetics, that diffuse coronary atherosclerosis would be a prominent issue, and a surgeon operating on an arrested heart is more likely to perform an anastomosis on such an impaired artery than a surgeon performing an off-pump procedure. Some surgical omissions cannot be excluded in such cases.

The absence of the obvious beneficial effect on stroke, in the early post-operative period, in the off-pump group was unexpected, because it has been assumed that the usage of clamp and aortic cannulation per se are the factors that present the greatest risk for development of an embolic cerebral event. Similar outcomes were also observed in elderly high-risk patients. A trend toward lower incidence of post-operative stroke among octogenarians in the offpump group was also present ${ }^{19}$. Somewhat surprisingly, we had better results than Houlind et al. in the DOORS study, $\left(4.0 \%\right.$ vs. $2.2 \%$, strokes during first 30 days) (ref. $\left.{ }^{20}\right)$.

The reduced number of grafts performed in the offpump group follows the general trend seen in similar studies: BBS ( 3.34 vs. $3.22, P=0.11)$, ROOBY ( $3.0 \pm 1.0$ vs. $2.9 \pm 0.9, P=0.002)$, Lemma et al. $(3.3 \pm 1.0$ vs. $3.0 \pm$ $1.1, P=0.001)$ as well as the CORONARY study. In addition, a meta-analysis of randomized trials found that off-pump CABG resulted in significantly fewer grafts ${ }^{21}$. An anastomosis of the lateral wall is an exacting procedure that could be burdened by the risk of wall injury due to the intramuscular course of the target artery. Where the coronary artery is heavily calcified, the surgeon might not be expected to make an anastomosis of the lateral wall or is more likely to convert to an on-pump procedure. Here it should be stated that our early results showed no relevant impact of this fact on clinical outcomes. In both groups we observed only one re-intervention during the first 30 post-operative days (Table 4).

As with the MI definition, the term "completeness of revascularization" is also not well defined and different studies employ different definitions. From the three main viewpoints (anatomic, functional and numeric) we used a definition that was more functional ${ }^{22}$. In many cases the objective status of the target artery does not correspond to the findings from selective coronary angiography (SCG), necessitating a change in surgical plans. Therefore we have no statistics about the planned number of grafts, which was determined by the surgeon and can only be partially considered an objective value. The extent of CAD did not differ between the two groups (Table 1). For this reason, it was expectable that there were more incomplete revascularizations in the off-pump group, due the lower number of bypasses (Table 2), for reasons previously described.

Compared to the formerly discussed, highly respected trials, the PRAGUE-6 trial includes a higher percentage of women (PRAGUE-6 40\%, CORONARY 20\%, ROOBY $0.5 \%)$ and more accurately reflects everyday practice.

\section{Mid-term results}

Contrary to expectations, our study did not confirm an unequivocal benefit for the off-pump technique after one year. Although the patients in the off-pump group showed an almost $10 \%$ lower incidence of major complications $(30.8 \%$ vs. $21.4 \%)$, the difference did not reach statistical significance $(P=0.117)$. The cause of the in- 
creased mortality rates of OPCAB patients between day 30 and the 1 year follow-up remains unclear, and needs to be studied further, because not all of the deaths can be considered cardiovascular-related. The 1 year follow-up data were collected retrospectively. Most of the deceased patients died in district hospitals without an autopsy, so the immediate cause of death would be speculative. Since off-pump procedures, in the unselected patient population, results in fewer patent saphenous grafts per patient at one year ( 0.7 patent anastomosis per patient vs. 1.1 patent anastomosis in the on-pump group $(P<0.01)\left(\right.$ ref. $\left.^{23}\right)$, and since vein-graft patency was significantly better in the on-pump group $(83.8 \%$ vs. $76.6 \%, P<0.001)\left(\right.$ ref. $\left.^{24}\right)$, it is possible that some of the deaths may have been associated with sudden cardiac events, even though we noticed no significant increase in myocardial infarctions over the same period. The incidence of coronary re-intervention also remained comparable in both groups $(2.8 \%$ and $5.1 \%$, Group $\mathrm{A}$ and $\mathrm{B}$, resp., $P=0.373)$. Our results are similar to 1-year follow-ups seen in the CORONARY trial. That study also showed no significant difference between groups of patients relative to the rate of primary composite endpoints ( $13.3 \%$ vs. $12.1 \%$, HR $0.91,95 \%$ CI $0.77-1.07, P=0.24)$, although less than 20 per cent of the participants were initially evaluated as being at high risk, as mentioned above ${ }^{25}$. That fact is certainly reflected in the lower incidence of primary endpoints in general, compared to our outcomes.

\section{Limitations}

Over 200 patients took part in our study. This could be perceived as a small sample which could limit the value of the information obtained. Additionally, the study was a single-center design and some of the results could have been influenced by country-specific circumstances and individual departmental practices, such as time of intubation, length of hospitalization and consideration of total hospital cost.

\section{CONCLUSIONS}

Our inclusion criteria created a rarely observed cohort of high-risk patients in which we could compare postoperative results after on-pump and off-pump coronary revascularization. Our hypothesis that high-risk patients would benefit from avoiding ECC, was not supported by the PRAGUE-6 study. However, it did show that off-pump surgery is associated with a lower incidence of serious complications, especially MI and global ischemia, during the first 30 post-operative days. It appears to be safer and should become the preferred technique for direct revascularization in extremely ill patients. In addition, from the point of view of the surgeon, the observed $\approx 10 \%$ lower incidence of major post-operative complications at 1 year could also impact the decision regarding which technique to use.

Acknowledgement: The PRAGUE-6 study was supported by "P35 - PRVOUK" - the Scientific Plan of Charles
University in Prague, the Czech Republic, granted by the Ministry of Health of the Czech Republic.

Author contributions: JH: study design, data collection and interpretation, manuscript writing, participating surgeon; ZS: study design, development of methodology, data interpretation, participating surgeon; SJ, PB: data collection and interpretation; TV: data collection and analysis, anaesthetist; MM: statistical analysis; PW: study design.

Conflict of interest statement: The authors state that there are no conflicts of interest regarding the publication of this article.

Meeting Presentation: American College of Cardiology Scientific Session, Late-Breaking Clinical Trials, San Francisco, CA, U.S.A., March 11th, 2013.

\section{REFERENCES}

1. Matata BM, Sosnowski AW, Galinanes M. Off-pump bypass graft operation significantly reduces stress and inflammation. Ann Thorac Surg 2000;69:785-91.

2. Czerny M, Baumer H, Kilo J, Lassnigg A, Hamwi A, Vukovich T, Wolner E, Grimm M. Inflammatory response and myocardial injury following coronary artery bypass grafting with and without cardiopulmonary bypass. Eur J Cardiothorac Surg 2000;17:737-42.

3. Calafiore AM, Di Mauro M, Canosa C, Di Giammarco G, laco AL, Contini M. Myocardial revascularization with and without cardiopulmonary bypass:advantages, disadvantages and similarities. Eur J Cardiothorac Surg 2003;24:953-60.

4. Angelini GD, Taylor FC, Reeves BC, Ascione R. Early and midterm outcome after off-pump and on-pump surgery in Beating Heart Against Cardioplegic Arrest Studies (BHACAS 1 and 2): a pooled analysis of two randomized controlled trials. Lancet 2002;359:1194-9.

5. Straka Z, Widimsky P, Jirasek K, Stros P, Votava J, Vanek T, Brucek P, Kolesar M, Spacek R. Off-pump versus on pump coronary surgery: final results from prospective randomized study Prague-4. Ann Thorac Surg 2004;77:789-93.

6. Shroyer AL, Grover FL, Hattler B, Collins JF, McDonald GO, Kozora E, Lucke JC, Baltz JH, Novitzky D. On-Pump versus Off-Pump CoronaryArtery Bypass Surgery. N Engl J Med 2009;361:1827-37.

7. Lamy A, Devereaux PJ, Prabhakaran D, Taggart DP, Hu S, Paolasso E, Straka Z, Piegas LS, Akar AR, Jain AR, Noiseux N, Padmanabhan C, Bahamondes JC, Novick RJ, Vaijyanath P, Reddy SK, Tao L, Olavegogeascoechea PA, Airan B, Sulling TA, Whitlock RP, Ou Y, Pogue J, Chrolavicius S, Yusuf S. Off-Pump or On-Pump CoronaryArtery Bypass Grafting at 30 Days. N Engl J Med 2012;366:1489-97.

8. Gaudino M, Glieca F, Alessandrini F, Nasso G, Pragliola C, Luciani N, Morelli M, Possati G. High risk coronary artery bypass patient: incidence, surgical strategies, and results. Ann Thorac Surg 2004;77:5749.

9. Puskas JD, Thourami VH, Kilgo P, Cooper W, Vassiliades T, Vega JD, Morris C, Chen E, Schmotzer BJ, Guyton RA, Lattouf OM. Off-Pump Coronary Artery Bypass Disproportionately Benefits High-Risk Patients. Ann Thorac Surg 2009;88:1142-7.

10. Abu-Omar Y, Taggart DP. The present status of off-pump coronary artery bypass grafting. Eur J Cardiothorac Surg 2009;36:312-21.

11. Vanek T, Brucek P, Straka Z. Fast track as a routine for open-heart surgery. Eur. J Cardiothorac Surg 2002;21(2):369-70.

12. Al-Attar N. Postoperative myocardial infarction. e-journal of the ESC Council for Cardiology Practice 2011;10, available at: http://www. escardio.org/communities/councils/ccp/e-journal/volume10/ Pages/Postoperative-myocardial-infarction-Nawwar-Al-Attar.aspx\#. UZuJbJ1luzk

13. Young-Nam Y, Young-Lan K, Kyung-Jong Y. Can the EuroSCORE Predict the Early and Mid-Term Mortality After Off-Pump Coronary Artery Bypass Grafting? Ann Thorac Surg 2007;83:2111-7.

14. Nilsson J, Algotsson L, Höglund P, Lührs C, Brandt J. Early Mortality in Coronary Bypass Surgery: the EuroSCORE Versus The Society of Thoracic Surgeons Risk Algoritm, Ann Thorac Surg 2004;77:1235-9.

15. Møller CH, Perko MJ, Lund JT, Andersen LW, Kelbæk H, Madsen JK, Winkel P, Gluud C, Steinbrüchel DA. No Major Differences in 30-Day 
Outcomes in High-Risk Patients Randomized to Off-Pump Versus On-Pump Corornary Bypass Surgery: The Best Bypass Surgery Trial. Circulation 2010;121:498-504.

16. Lemma MG, Coscioni E, Tritto FP, Centofanti P, Fondacone C, Salica A Rossi A, De Santo T, Di Benedetto G, Piazza L, Rinaldi M, Schinosa AL, De Paulis R, Contino M, Genoni M. On-pump versus off-pump coronary artery bypass surgery in high-risk patients: Operative results of a prospective randomized trial (on-off study). J Thorac Cardiovasc Surg 2012;143:625-31.

17. Paparella D, Cappabianca G, Malvindi P, Paramythiotis A, Galeone A, Veneziani N, Fondacone C, de Luca Tupputi Schinosa L. Myocardial injury after off-pump coronary artery bypass grafting operation. Eur J Cardiothorac Surg 2007;32:481-7.

18. Yau JM, Alexander JH, Hafley G, Mahaffey KW, Mack MJ, Kouchoukos N, Goyal A, Peterson ED, Gibson CM, Califf RM, Harrington RA Ferguson TB, PREVENT IV Investigators. Impact of perioperative myocardial infarction on angiographic and clinical outcomes following coronary artery bypass grafting. Am J Cardiol 2008;102:546-51.

19. Vasques F, Rainio A, Heikkinen J, Mikkola R, Lahtinen J, Kettunen U, Juvonen T, Biancari F. Off-pump versus on-pump coronary artery bypass surgery in patients aged 80 years and older: institutional results and meta-analysis. Heart Vessels 2013;28:46-56.

20. Houlind K, Kjeldsen BJ, Madsen SN, Rasmussen BS, Holme SJ, Nielsen $\mathrm{PH}$, Mortensen PE. On-pump versus off-pump coronary artery bypass surgery in elderly patients: results from the Danish On-Pump versus Off-Pump Randomization Study. Circulation 2012;125:2431-9.
21. Møller CH, Penninga L, Wetterslev J, Steinbrüchel DA, Gluud C. Clinical outcomes in randomized trials of off- vs. on-pump coronary artery bypass surgery: systematic review with meta-analyses and trial sequential analyses. Eur Heart J 2008;29:2601-16.

22. Ong ATL, Serruys PW. Complete Revascularisation. Circulation. 2006;114:249-55.

23. Widimsky P, Straka Z, Stros P, Jirasek K, Dvorak J, Votava J, Lisa L, Budesinsky T, Kolesar M, Vanek T, Brucek P. One-year coronary bypass graft patency: a randomized comparison between off-pump and on-pump surgery angiographic results of the PRAGUE-4 trial. Circulation. 2004;110(22):3418.

24. Puskas JD, Williams WH, Mahoney EM, Huber PR, Block PC, Duke PG, Staples JR, Glas KE, Marshall JJ, Leimbach ME, McCall SA, Petersen RJ, Bailey DE, Weintraub WS, Guyton RA. Off-pump vs conventional coronary artery bypass grafting: early and 1-year graft patency, cost, and quality-of-life outcomes: a randomized trial. JAMA. 2004:291:1841-9.

25. Lamy A, Devereaux PJ, Prabhakaran D, Taggart DP, Hu S, Paolasso E, Straka Z, Piegas LS, Akar AR, Jain AR, Noiseux N, Padmanabhan C, Bahamondes JC, Novick RJ, Vaijyanath P, Reddy SK, Tao L, Olavegogeascoechea PA, Airan B, Sulling TA, Whitlock RP, Ou Y, Pogue J, Chrolavicius S, Yusuf S. Effects of Off-Pump and OnPump Coronary-Artery Bypass Grafting at 1 Year. N Engl J Med 2013;368:1179-88. 